\section{ECCOMAS}

\section{Proceedia}

COMPDYN 2017

$6^{\text {th }}$ ECCOMAS Thematic Conference on Computational Methods in Structural Dynamics and Earthquake Engineering M. Papadrakakis, M. Fragiadakis (eds.) Rhodes Island, Greece, 15-17 June, 2017

\title{
VULNERABILITY ASSESSMENT OF FLAG-SHAPED HYSTERETIC ROCKING BRIDGE BENTS
}

\author{
Anastasios I. Giouvanidis $^{1}$, Michalis Fragiadakis ${ }^{2}$ and Elias G. Dimitrakopoulos ${ }^{1}$ \\ ${ }^{1}$ Department of Civil and Environmental Engineering, The Hong Kong University of Science and \\ Technology \\ Kowloon Bay, Hong Kong \\ e-mail: agiouvanidis@ connect.ust.hk \\ e-mail: ilias@ust.hk \\ ${ }^{2}$ School of Civil Engineering, National Technical University of Athens \\ GR 15780, Athens, Greece \\ e-mail: mfrag@mail.ntua.gr
}

Keywords: rocking, flag-shaped hysteretic behavior, prefabricated bridges, seismic resistant structures, fragility curves, vulnerability assessment.

\begin{abstract}
Rocking motion implies that a structure under seismic loading exhibits rigid body rotation around pre-defined pivot points. Its stability primarily relies on utilizing the rotational inertia through (purposely) activated dynamic motion. This paper focuses on slender bridge frames that exhibit rigid planar rocking behavior. It examines rocking frames enhanced with elastic central tendons to provide supplemental re-centering capacity and buckling-restrained braces to dissipate seismic energy; transforming a freestanding frame into a hybrid rocking frame with flag-shaped hysteretic behavior. The objective of this study is twofold. Firstly, it investigates the existence of 'optimal' intensity measures for hybrid rocking structures by examining their 'practicality', 'efficiency' and 'sufficiency' with an appropriate engineering demand parameter. The analysis shows that the slenderness-based intensity measures reduce the scatter on the response and they exhibit independence from seismic hazard parameters. Further, this study also focuses on the seismic vulnerability assessment of the examined freestanding and hybrid rocking frames. To assess their seismic performance, the analysis employs a suite of recorded earthquakes and performs a parametric investigation in terms of the vulnerability of different structural configurations. This paper develops analytical fragility curves based on the most 'optimal' scalar intensity measures. The results reveal the mitigated fragility of the positive stiffness rocking frame compared to the other structural systems. For some intensity measures though, this seismic enhancement becomes marginal. Hence, a more sophisticated approach would require the introduction of a second engineering demand parameter tailored to the needs of hybrid rocking structures or an appropriate vector intensity measure.
\end{abstract}




\section{INTRODUCTION}

Rocking as a means of seismic isolation is attracting research interest for almost a century (see e.g., [26] and references therein). Even though the existing rocking structures remain scarce (e.g., [38, 41] among others), currently, there is an increasing need to examine the response of freestanding $[15,39,12,2,13,46,48,19,49]$ as well as controlled rocking structures $[16,21,32,17,24]$ adopting classical or more sophisticated methods $([1,47,44,3,22]$ among others). From a practical point of view, the rocking frame of Fig. 1, proposed originally by Mander and Cheng [33] as a 'damage avoidance design', is gaining momentum in bridge engineering and its seismic behavior is extensively examined. In particular, [30, 31] showed that the stability of the rigid rocking bridge frame is enhanced, the more heavy its cap-beam is. Its stability primarily stems from the mobilization of its rotational inertia. Further, [11, 42] revealed that rocking piers can exhibit large drifts with minor damage and/or residual displacements. Recent experimental studies $[43,37]$ proved the negligible residual drifts of a posttensioned rocking column compared to the pertinent drifts of a conventional monolithic column $(0.4 \%$ versus $6.8 \%$ respectively). To minimize further the residual deformations many researchers (see e.g., [24] and references therein) combined the use of additional re-centering with energy dissipation devices, proposing 'hybrid rocking systems' which exhibit flag-shaped hysteretic behavior (FSHB). Giouvanidis and Dimitrakopoulos [24] revealed the diverse influence of the prestressing tendon's force. Prestressing the tendons might be beneficial for small rocking rotations, but could become detrimental for large rocking rotations; a counter-intuitive behavior.

Even though it is hard to overstate the significance of the deterministic methods in investigating the rocking behavior $[15,19]$, it is beneficial to complement them with a probabilistic evaluation of the (seismic) rocking response. In this context, Dimitrakopoulos and Paraskeva [18] proposed normalized fragility curves that estimate the overturning tendency of freestanding rocking structures and unveiled the existence of a critical peak ground acceleration, above and below which the rocking response scales differently. Building on previous work [23, 24], the present study: (i) investigates the existence of 'optimal' intensity measures (IMs) for hybrid rocking structures and (ii) compares the seismic fragility of hybrid rocking bridge frames with different post-uplift lateral stiffness (i.e., negative, zero, or positive) with the archetypal freestanding frame.

\section{DYNAMICS OF THE HYBRID ROCKING BRIDGE FRAME}

This section focuses on the analytical modelling of a rocking bridge frame which exhibits flag-shaped hysteretic behavior (FSHB). Consider the rocking frame of Fig. 1 enhanced with central (linear-elastic) slack (unbonded) tendons and (nonlinear-hysteretic) buckling restrained braces (BRBs) at the bottom of the piers (Fig. 1(c)). In the absence of a ground excitation, the frame remains in full contact with the ground (Fig. 1(a)). In the event of a ground shaking though, when the seismic demand (i.e., overturning moment due to the ground excitation) exceeds the static seismic resistance (i.e., restoring moment due to the gravity) the frame initiates rocking motion (Fig. 1(b)). In particular, rocking commences when the ground acceleration becomes $\ddot{u}_{g, \min }=g \tan \alpha[17,24]$.

This study assumes (rigid) planar rocking motion. It also ignores the sliding between the contacting bodies and the fracture of the supplemental devices (i.e., tendons and/or dissipaters). Note that, the former is covered in [10] and the latter in [17].

Further, the Bouc-Wen model $[9,50]$ is adopted to describe the hysteretic behavior of the BRBs. The restoring dissipating force $F_{D}$ and the dimensionless hysteretic parameter $z(t)$ are 


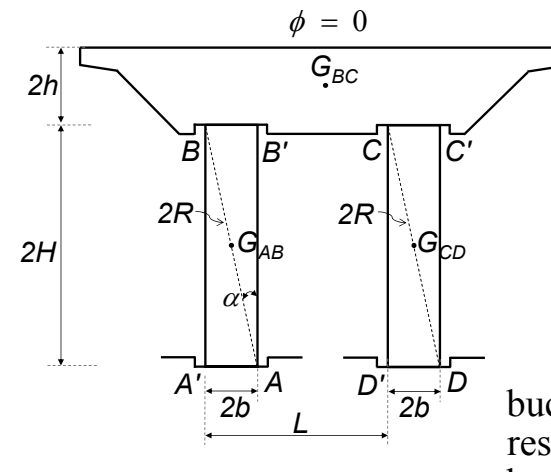

(a)

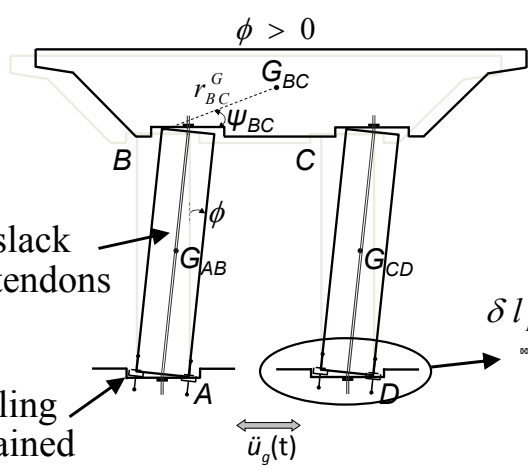

(b)

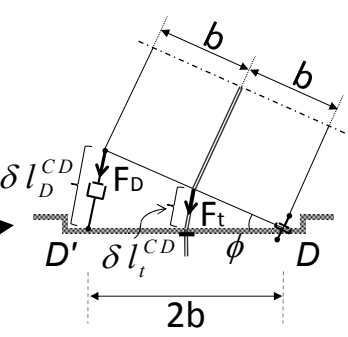

(c)

Figure 1: The examined rocking bridge frame (a) at rest position, (b) during clockwise (positive) rotation and (c) detail of the column-foundation connection.

expressed accordingly as [24]:

$$
\begin{gathered}
F_{D}=\varepsilon k_{d} u(t)+(1-\varepsilon) k_{d} u_{y} z(t) \\
\dot{z}(t)=\frac{1}{u_{y}}\left[\dot{u}(t)-\gamma|\dot{u}(t)| z(t)|z(t)|^{n-1}-\beta \dot{u}(t)|z(t)|^{n}\right]
\end{gathered}
$$

where $\varepsilon$ is the post-yield to pre-yield elastic stiffness $\left(k_{d}\right)$ ratio of the BRBs and is taken equal to $\varepsilon=0.025$ [8]. $u(t)$ is the axial deformation of the brace, $u_{y}$ is the yield deformation equal to $u_{y}=\delta l_{D_{y}}=4 b \sin \left(\phi_{y} / 2\right)$ (Fig. 1(c)). $b$ is the half-width of the base of the column of the frame and $\phi_{y}$ is the yield rotation. Parameters $\beta, \gamma$ and $n$ control the shape of the hysteretic loop. The present work assumes $\beta=0.55, \gamma=0.45, n=1$ [8].

When rocking initiates, the tendon deforms. The elongation of each tendon is equal to the sum of the elongations at the bottom and the top of each tendon: $\delta l_{t}=4 b \sin (\phi / 2)$ (Fig. 1(c)). The equation of motion of the hybrid rocking frame is [24]:

$$
\ddot{\phi}=-\frac{1+2 \gamma_{m}}{1+3 \gamma_{m}} p^{2}\left[\begin{array}{l}
\sin (\alpha \operatorname{sgn}(\phi)-\phi)+\frac{\ddot{u}_{g}}{g} \cos (\alpha \operatorname{sgn}(\phi)-\phi) \\
+4\left(\rho_{t}+\varepsilon \rho_{d}\right) \sin \phi+8(1-\varepsilon) \rho_{d} \sin \frac{\phi_{y}}{2} \cos \frac{\phi}{2} z(t)
\end{array}\right]
$$

where $\phi$ is the generalized coordinate which describes the rocking motion of the frame (Fig. 1). $p$ is the frequency parameter of the column of the frame which takes the form: $p=\sqrt{3 g / 4 R}$ for rectangular columns, where $g$ is the acceleration of gravity and $R$ is the half-diagonal length of the column of the frame. $\alpha$ is the slenderness of the column (Fig. 1). $\operatorname{sgn}(\phi)$ is the sign function and $\gamma_{m}=m_{B C} / 2 m_{A B}$ is the mass ratio, with $m_{A B}$ and $m_{B C}$ the masses of the column $A B$ and the cap-beam $B C$ respectively. The dimensionless parameters $\rho_{d}=k_{d} b^{2} /\left(m_{A B}+m_{B C}\right) g R$ and $\rho_{t}=k_{t} b^{2} /\left(m_{A B}+m_{B C}\right) g R$ depend on the stiffness $k_{d}$ of the dissipater and $k_{t}$ of the tendon respectively. The present study assumes the stiffness $k_{d}$ of the dissipater is constant $\left(\rho_{d}=3\right)$, whereas the stiffness $k_{t}$ of the tendon, and subsequently the parameter $\rho_{t}$, varies within $0.001 \leq \rho_{t} \leq 0.55$ providing different hybrid frames with respect to their overall stiffness, i.e., negative, zero and/or positive post-uplift lateral stiffness [24] (Fig. 2).

During rocking, each time the rotation reverses, an impact occurs and energy is lost. This study adopts a coefficient $\eta$ equal to 0.92 to capture the energy loss at each impact. For a more careful analysis of the coefficient of restitution for various frame configurations the reader is referred to [17]. 

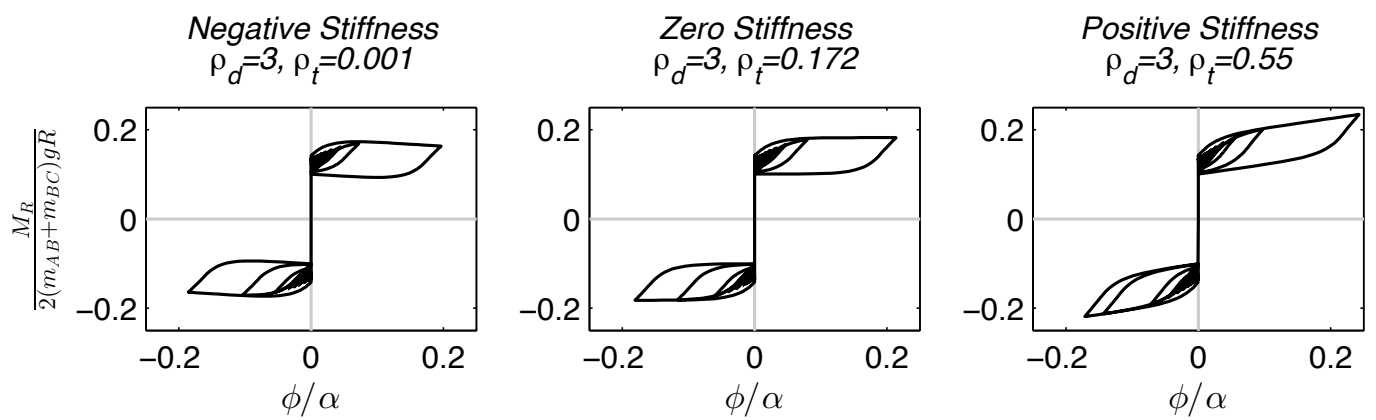

Figure 2: Flag-shaped hysteretic behavior of the rocking frame of Fig. 1 when subjected to an M\&P pulse [34] with $\nu_{g}=45^{\circ}, \gamma_{g}=2.0, \alpha_{g} / g=0.6$ and $\omega_{g} / p=5.0 . M_{R}$ is the total restoring moment due to the forces from gravity, tendons and dissipaters, whereas the dimensionless parameters $\rho_{d}$ and $\rho_{t}$ depend on the stiffness of the dissipater and the tendon respectively [24].

\section{SEISMIC VULNERABILITY ANALYSIS OF THE HYBRID ROCKING FRAME}

\subsection{Engineering demand parameter and intensity measures}

This section investigates the seismic fragility of rocking bridge frames with different dynamic characteristics, i.e., negative, zero or positive post-uplift lateral stiffness when subjected to a suite of recorded earthquakes (Table 1). Consider the bridge frame of Fig. 1. Assume the frame has a cap-beam of $13 \mathrm{~m}$ width and $2 h=1 \mathrm{~m}$ height [33]. The two square columns have the same base-width $2 b=1 \mathrm{~m}$, the same density and height $2 H=7 \mathrm{~m}[33,17]$. Both columns have the same slenderness $\alpha \simeq 8^{\circ}$ and frequency parameter $p=1.44 \mathrm{rad} / \mathrm{s}$, while the distance between them is $L=8 \mathrm{~m}$. The cap-beam/column mass ratio $\left(\gamma_{m}\right)$ is 5 [33, 24]. Further, the tendons are assumed to be slack, anchored into the cap- and foundation-beam a depth of 0.75 $\mathrm{m}$ [33]. Following [8], the yield displacement $\left(u_{y}\right)$ of the BRBs is taken as $3.5 \mathrm{~mm}$, which corresponds to a yield rotation $\phi_{y} / \alpha \simeq 0.025$.

To effectively examine the seismic fragility of the rocking frame, this section: (i) introduces an appropriate engineering demand parameter (EDP) and the corresponding limit states (LSs) and (ii) investigates the existence of 'optimal' intensity measures (IMs) for hybrid rocking structures by investigating their 'practicality', 'efficiency' and 'sufficiency' [36, 28]. 'Practicality' is measured by the slope $b_{R}$ of the regression after conducting cloud analysis (as Fig. 3 shows later on). Specifically, the larger the $b_{R}$ the more 'practical' the IM [36]. An 'efficient' IM reduces the scatter (or dispersion) of the estimated structural demand $[25,28,36]$. On the other hand, a 'sufficient' IM offers an estimation of the structural demand independent of seismic hazard parameters, such as magnitude $M_{w}$, distance from the fault $R_{\text {rup }}$ [28], or epsilon $\epsilon$ [5].

Engineering Demand Parameter (EDP): According to the assumptions of the present study, an appropriate EDP to describe the motion of the rocking frame of Fig. 1 is the absolute value of the peak rotation $\phi_{\max }$ normalized with the slenderness $\alpha$ of the column [18].

$$
E D P=\frac{\left|\phi_{\max }\right|}{\alpha}
$$

This work also proposes three limit states (LSs) (Table 2). The exceedance of the first LS $(\mathrm{EDP}>0)$ implies rocking initiation. The second LS corresponds to a design column drift 
Table 1: Recorded earthquakes [45].

\begin{tabular}{|c|c|c|c|c|c|c|c|}
\hline No & Event & Station & $\phi^{\circ 1}$ & Soil $^{2}$ & $M_{w}{ }^{3}$ & $R_{\text {rup }}{ }^{4}(\mathrm{~km})$ & $P G A(\mathrm{~g})$ \\
\hline 1 & Loma Prieta, 1989 & Agnews State Hospital & 090 & C,D & 6.9 & 28.2 & 0.159 \\
\hline 2 & Northridge, 1994 & LA, Baldwin Hills & 090 & $\mathrm{~B}, \mathrm{~B}$ & 6.7 & 31.3 & 0.239 \\
\hline 3 & Imperial Valley, 1979 & Compuertas & 285 & $\mathrm{C}, \mathrm{D}$ & 6.5 & 32.6 & 0.147 \\
\hline 4 & Imperial Valley, 1979 & Plaster City & 135 & C,D & 6.5 & 31.7 & 0.057 \\
\hline 5 & Loma Prieta, 1989 & Hollister Diff. Array & 255 &,$- \mathrm{D}$ & 6.9 & 25.8 & 0.279 \\
\hline 6 & San Fernando, 1971 & LA, Hollywood Stor. Lot & 180 & $\mathrm{C}, \mathrm{D}$ & 6.6 & 21.2 & 0.174 \\
\hline 7 & Loma Prieta, 1989 & Anderson Dam Downstrm & 270 & $\mathrm{~B}, \mathrm{D}$ & 6.9 & 21.4 & 0.244 \\
\hline 8 & Loma Prieta, 1989 & Coyote Lake Dam Downstrm & 285 & $\mathrm{~B}, \mathrm{D}$ & 6.9 & 22.3 & 0.179 \\
\hline 9 & Imperial Valley, 1979 & El Centro Array \#12 & 140 & C,D & 6.5 & 18.2 & 0.143 \\
\hline 10 & Imperial Valley, 1979 & Cucapah & 085 & $\mathrm{C}, \mathrm{D}$ & 6.5 & 23.6 & 0.309 \\
\hline 11 & Northridge, 1994 & LA, Hollywood Storage FF & 360 & C,D & 6.7 & 25.5 & 0.358 \\
\hline 12 & Loma Prieta, 1989 & Sunnyvale Colton Ave & 270 & C,D & 6.9 & 28.8 & 0.207 \\
\hline 13 & Loma Prieta, 1989 & Anderson Dam Downstrm & 360 & B,D & 6.9 & 21.4 & 0.24 \\
\hline 14 & Imperial Valley, 1979 & Chihuahua & 012 & $\mathrm{C}, \mathrm{D}$ & 6.5 & 28.7 & 0.27 \\
\hline 15 & Imperial Valley, 1979 & El Centro Array \#13 & 230 & $\mathrm{C}, \mathrm{D}$ & 6.5 & 21.9 & 0.139 \\
\hline 16 & Imperial Valley, 1979 & Westmoreland Fire Station & 090 & C,D & 6.5 & 15.1 & 0.074 \\
\hline 17 & Loma Prieta, 1989 & Hollister South \& Pine & 000 &,$- \mathrm{D}$ & 6.9 & 28.8 & 0.371 \\
\hline 18 & Loma Prieta, 1989 & Sunnyvale Colton Ave & 360 & C,D & 6.9 & 28.8 & 0.209 \\
\hline 19 & Superstition Hills, 1987 & Wildlife Liquefaction Array & 090 & C,D & 6.7 & 24.4 & 0.18 \\
\hline 20 & Imperial Valley, 1979 & Chihuahua & 282 & C,D & 6.5 & 28.7 & 0.254 \\
\hline 21 & Imperial Valley, 1979 & El Centro Array \#13 & 230 & $\mathrm{C}, \mathrm{D}$ & 6.5 & 21.9 & 0.139 \\
\hline 22 & Imperial Valley, 1979 & Westmoreland Fire Station & 180 & C,D & 6.5 & 15.1 & 0.11 \\
\hline 23 & Loma Prieta, 1989 & Halls Valley & 090 & $\mathrm{C}, \mathrm{C}$ & 6.9 & 31.6 & 0.103 \\
\hline 24 & Loma Prieta, 1989 & WAHO & 000 &,$- \mathrm{D}$ & 6.9 & 16.9 & 0.37 \\
\hline 25 & Superstition Hills, 1987 & Wildlife Liquefaction Array & 360 & C,D & 6.7 & 24.4 & 0.2 \\
\hline 26 & Imperial Valley, 1979 & Compuertas & 015 & $\mathrm{C}, \mathrm{D}$ & 6.5 & 32.6 & 0.186 \\
\hline 27 & Imperial Valley, 1979 & Plaster City & 045 & C,D & 6.5 & 31.7 & 0.042 \\
\hline 28 & Loma Prieta, 1989 & Hollister Diff. Array & 165 &,$- \mathrm{D}$ & 6.9 & 25.8 & 0.269 \\
\hline 29 & San Fernando, 1971 & LA, Hollywood Stor. Lot & 090 & C,D & 6.6 & 21.2 & 0.21 \\
\hline 30 & Loma Prieta, 1989 & WAHO & 090 &,$- \mathrm{D}$ & 6.9 & 16.9 & 0.638 \\
\hline
\end{tabular}

${ }^{1}$ Component $\quad{ }^{2}$ USGS, Geomatrix soil class $\quad{ }^{3}$ Moment magnitude $\quad{ }^{4}$ Closest distance to fault rupture

of $5 \%$ [33], which corresponds to a column rotation $\phi / \alpha \simeq 0.35$. This limit state indicates intermediate (observable) rocking action with potential local damage to the contact points, but without substantial danger of overturning. The third LS represents the maximum column drift of $11 \%$ [33], which corresponds to a column rotation $\phi / \alpha \simeq 0.8$, and herein is assumed that it leads to unstable configurations, potentially critical to the overturning (or failure) of the frame (Table 2).

Table 2: Proposed limit states.

\begin{tabular}{lccc}
\hline LSs $^{1}$ & EDP $^{2}$ & Capacity limit states & Description \\
\hline LS1 & 0.0 & Rocking initiation & Uplifting \\
LS2 & 0.35 & Intermediate (observable) rocking action & Local damage due to contact \\
LS3 & 0.8 & Large rocking action & Unstable configuration (critical to overturning) \\
\hline
\end{tabular}

${ }^{1}$ Limit States, ${ }^{2}$ Engineering Demand Parameter 
Table 3: Examined intensity measures.

\begin{tabular}{lc}
\hline Category & Intensity Measure (IM) \\
\hline Slenderness-based & $\begin{array}{c}I M_{1}=\frac{P G A}{g \tan \alpha}, I M_{2}=\frac{p P G V}{g \tan \alpha}, I M_{3}=\frac{p^{2} P G D}{g \tan \alpha}, \\
\\
I M_{4}=\frac{\omega_{m} P G V}{g \tan \alpha}, I M_{5}=\frac{A_{R M S}}{g \tan \alpha}, I M_{6}=\frac{p C A V}{g \tan \alpha}\end{array}$ \\
\hline Frequency-based & $I M_{7}=\frac{P G A}{p P G V}$ \\
\hline Energy-based & $I M_{8}=\frac{I_{F}}{p^{0.75} R}, I M_{9}=\frac{L_{e}}{R}$ \\
\hline
\end{tabular}

Intensity Measures (IMs): The identification of appropriate IMs for rocking structures is a far from trivial challenge. Dimitrakopoulos and Paraskeva [18] proposed 'optimal' IMs for (freestanding) rocking structures exhibiting negative post-uplift lateral stiffness. They showed the superior performance of the slenderness-based IMs compared to the frequency-based IMs. This paper, extends [18] and examines (hybrid) FSHB rocking frames with negative, zero and/or positive stiffness considering also energy-based IMs. Table 3 summarizes the examined IMs. $P G A, P G V$ and $P G D$ are the peak ground acceleration, peak ground velocity and peak ground displacement respectively. $C A V$ is the cumulative absolute velocity which equals the area under the (absolute) acceleration versus duration curve [27]. A strong ground motion parameter which includes the effects of the amplitude and frequency of a ground excitation is the root-mean-square acceleration $A_{R M S}$ [27]. $I_{F}$ is the Fajfar index which combines the peak ground velocity and the duration of strong motion [20]. $\omega_{m}$ denotes the mean frequency of the excitation [40], and $L_{e}$ is the energetic length-scale, firstly introduced for pulse-type ground motions [29] and later extended for non-distinct-pulse records [14].

\subsection{Seismic analysis}

This section employs the earthquake records of Table 1 and investigates the 'practicality', 'efficiency' and 'sufficiency' of the adopted IMs (Table 3) in capturing the behavior of the hybrid FSHB rocking frame of Fig. 1. Fig. 3 plots the EDP values $\left|\phi_{\max }\right| / \alpha$ versus the examined IMs when the hybrid frames of Fig. 1 are subjected to the records of Table 1 . This type of analysis is known as cloud analysis, where regression on IM-EDP plane is performed. The values
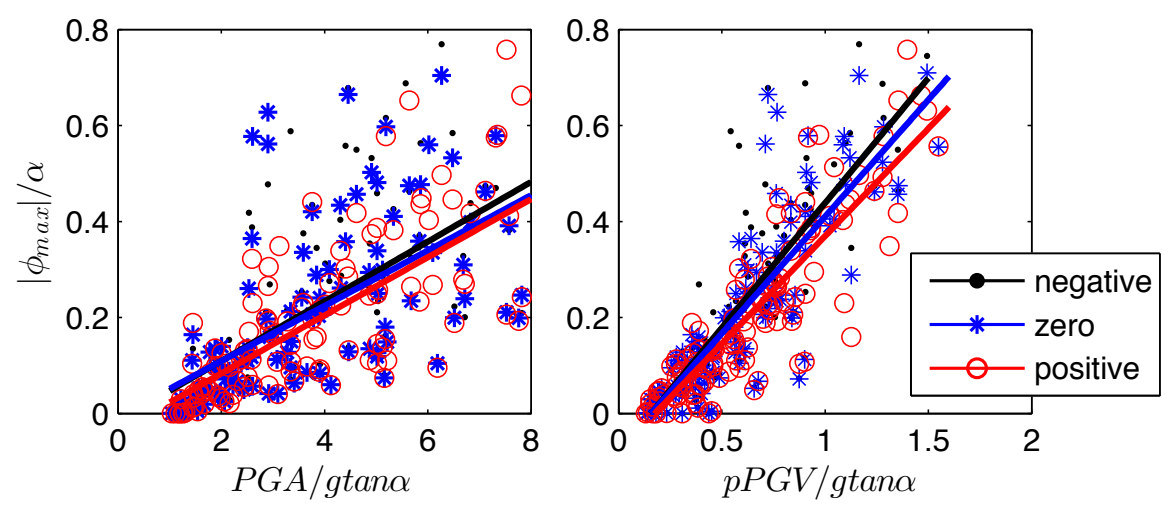

Figure 3: Cloud analysis of the 'safe rocking' cases of the hybrid FSHB rocking frames. Table 4 summarizes the results from the regression analysis for all the the examined IMs of Table 3. 
Table 4: Results from cloud analysis of the different hybrid FSHB rocking frames of Fig. $1 . b_{R}$ denotes the slope of the linear regression and is a measure of 'practicality'. The larger the $b_{R}$ the more 'practical' the IM [36]. $R^{2}$ is the coefficient of determination and is an indication of 'efficiency', i.e., the larger the $R^{2}$ the smaller the scatter (or dispersion) on the response and hence the more 'efficient' the IM [28]. The values in the Table are determined after linear regression analysis in logarithmic scale.

\begin{tabular}{lcccccc}
\hline \multirow{2}{*}{$\mathrm{IMs}^{1}$} & \multicolumn{2}{c}{ Negative } & \multicolumn{2}{c}{ Zero } & \multicolumn{2}{c}{ Positive } \\
\cline { 2 - 7 } & $R^{2}$ & $b_{R}$ & $R^{2}$ & $b_{R}$ & $R^{2}$ & $b_{R}$ \\
\hline$P G A / g \tan \alpha$ & $\mathbf{0 . 5 3 3}$ & $\mathbf{2 . 3 6 9}$ & $\mathbf{0 . 5 2 0}$ & $\mathbf{2 . 2 9 6}$ & $\mathbf{0 . 5 4 2}$ & $\mathbf{2 . 2 5 6}$ \\
$p P G V / g \tan \alpha$ & $\mathbf{0 . 4 9 0}$ & 2.282 & $\mathbf{0 . 4 9 7}$ & 2.226 & $\mathbf{0 . 5 0 7}$ & 2.137 \\
$p^{2} P G D / g \tan \alpha$ & 0.265 & 1.328 & 0.265 & 1.275 & 0.274 & 1.215 \\
$\omega_{m} P G V / g \tan \alpha$ & 0.436 & 2.054 & 0.435 & 2.008 & 0.461 & 1.987 \\
$A_{R M S} / g \tan \alpha$ & 0.486 & 2.334 & 0.473 & 2.251 & 0.498 & 2.217 \\
$p C A V / g \tan \alpha$ & $\mathbf{0 . 5 3 9}$ & $\mathbf{2 . 4 2 4}$ & $\mathbf{0 . 5 3 0}$ & $\mathbf{2 . 3 4 1}$ & $\mathbf{0 . 5 5 0}$ & $\mathbf{2 . 3 1 3}$ \\
$P G A / p P G V$ & 0.003 & 0.288 & 0.000 & 0.082 & 0.000 & 0.064 \\
$I_{F} / p^{0.75} R$ & $\mathbf{0 . 4 5 5}$ & 2.114 & $\mathbf{0 . 4 6 2}$ & 2.057 & $\mathbf{0 . 4 6 9}$ & 1.978 \\
$L_{e} / R$ & 0.254 & 1.103 & 0.257 & 1.075 & 0.256 & 1.018 \\
\hline
\end{tabular}

${ }^{1}$ Intensity Measures (Table 3)

of the EDP in Fig. 3 correspond to the 'safe rocking' cases, i.e., where the EDP exceeds the LS1 but not the LS3 (Table 2)). To minimize the effects of scaling the amplitudes of the earthquake records of Table 1 are scaled up to a scale factor of 6 . Table 4 summarizes the results from the linear regression analysis for all the proposed IMs. $R^{2}$ is the coefficient of determination which is considered as an indication of the 'efficiency', since the higher the $R^{2}$, the lower the $\beta_{\ln (E D P) \mid I M}$ (or dispersion) and therefore the more 'efficient' the IM [28, 36]. Recall that, $b_{R}$ represents the slope of the linear regression analysis and it is a measure of 'practicality'; the higher the $b_{R}$ the more 'practical' the IM [36]. Table 4 shows that the more 'practical' IMs are the slenderness-based IMs, i.e., $I M_{1}=P G A / g \tan \alpha$ and $I M_{6}=p C A V / g \tan \alpha$, with the $I M_{2}=p P G V / g \tan \alpha$ and $I M_{5}=A_{R M S} / g \tan \alpha$ to show similar 'practicality'. Further, Table 4 also unveils that the normalized Fajfar index $I M_{8}=I_{F} / p^{0.75} R$ together with most of the slenderness-based IMs maximize the coefficient of determination $R^{2}$, which is an indication of their 'efficiency'.

Multi-stripe analysis is an alternative to cloud analysis that provides a better indication of the 'efficiency' and 'sufficiency' of the proposed IMs (Fig. 3 and Table 3) [28]. Multi-stripe analysis scales the ground motions to a specified level of IM $[6,7]$. For the purposes of the present section, the records of Table 1 are scaled with a factor between 0.4 and 6.5. Postprocessing the EDP values we obtain results that are inherently conditional on the IM.

Fig. 4 plots the logarithmic standard deviation $\beta_{\ln (E D P) \mid I M}$ conditional on each IM level. In particular, it shows that the variation of the standard deviation $\beta_{\ln (E D P) \mid I M}$ among the different hybrid rocking frames is not significant. Therefore, under the assumptions of the present study, the 'efficiency' of the examined IMs remains unaffected by the different rocking frames. Further, Fig. 4 illustrates the 'inefficiency' of the frequency-based IM (i.e., $I M_{7}=P G A / p P G V$ ), since it consistently predicts high dispersion on the response (i.e., $\beta_{\ln (E D P) \mid(P G A / p P G V)}>1$ ). Similarly, $I M_{9}=L_{e} / R$ also shows high $\beta_{\ln (E D P) \mid\left(L_{e} / R\right)}$, and hence it is regarded as 'insufficient' as well. On the contrary, the slenderness-based IMs (i.e., from $I M_{1}=P G A / g$ tan $\alpha$ to $I M_{6}=p C A V / g \tan \alpha$ in Table 3) and the energy-based $I M_{8}=I_{F} / p^{0.75} R$ estimate the rocking response with low dispersion (i.e., $\beta_{\ln (E D P) \mid I M}<1$ ), and therefore, they are considered as 'efficient'. Note in Fig. 4 that, for low IM levels the value of the EDP decreases, hence the 

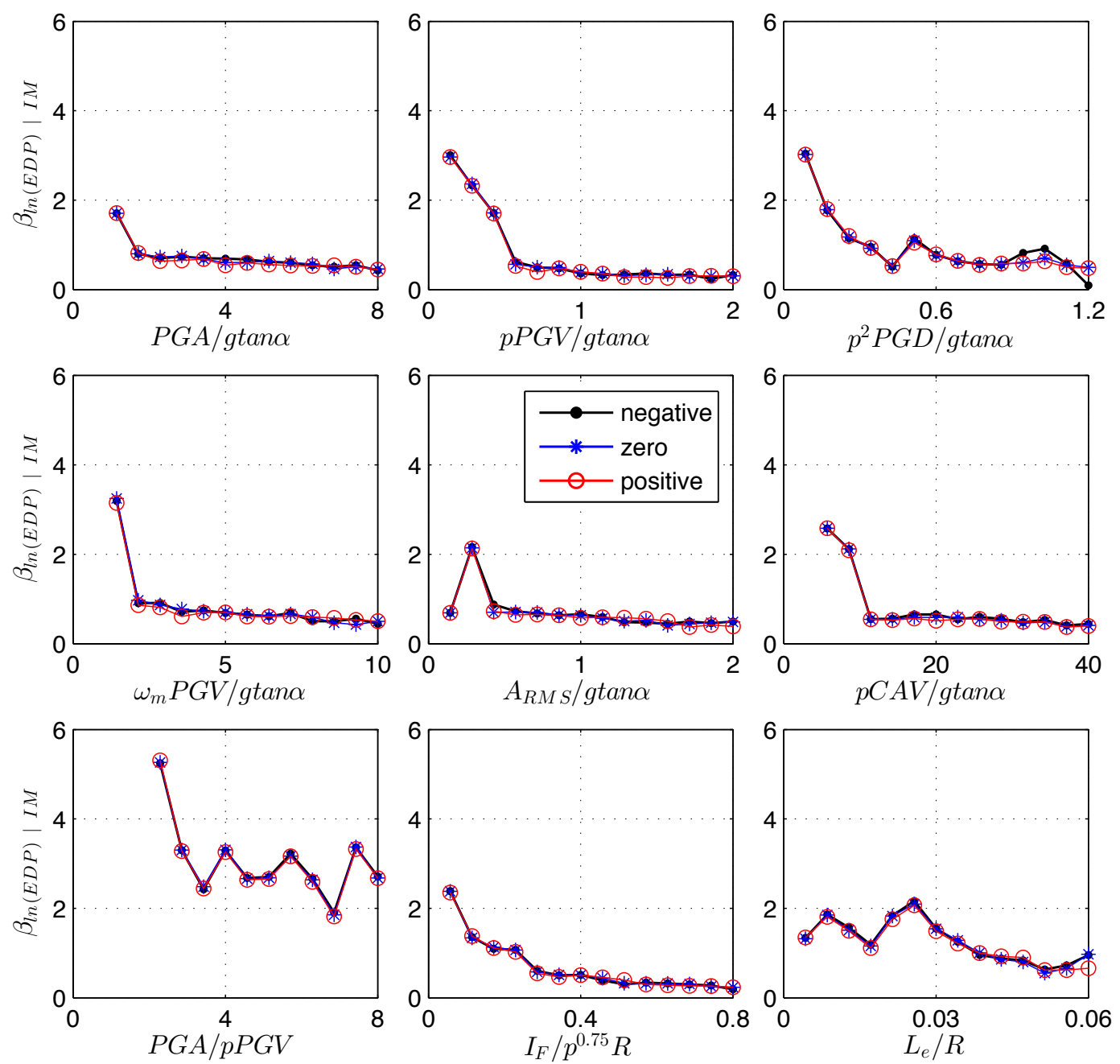

Figure 4: Logarithmic standard deviation $\beta_{\ln (E D P) \mid I M}$ conditional on each IM level of the 'safe rocking' cases of the hybrid frames of Fig. 1 with negative, zero and positive lateral stiffness. $\beta_{\ln (E D P) \mid I M}$ is a measure of 'efficiency' of every IM. The lower the $\beta_{\ln (E D P) \mid I M}$ the more 'efficient' the IM [28].

logarithmic standard deviation $\beta_{\ln (E D P) \mid I M}$ increases regardless of the examined IM.

On the other hand, 'sufficiency' provides an indication that an IM can be used independently of the seismological (or seismic hazard) parameters such as the magnitude $M_{w}$, the distance from the fault $R_{\text {rup }}$ [28] and/or epsilon $\epsilon$ [5]. Figs 5 to 7 plot the seismic response of the adopted hybrid FSHB rocking frames at various IM levels for all the examined IMs of Table 3 with respect to the distance from the fault $R_{\text {rup }}$ (Table 1). Constants $c_{n}, c_{z}$ and $c_{p}$ denote the slope of the regression analysis for the negative, zero and positive stiffness hybrid frames respectively. The closer the absolute value of the slope to zero, the more 'sufficient' the IM [28]. Note that, the present section investigates the 'sufficiency' of the IMs only with respect to the $R_{\text {rup }}$ and not e.g., the magnitude $M_{w}$ or the epsilon $\epsilon$ parameter. Specifically, Figs 5 and 6 plot the slenderness-based IMs, while Fig. (7) the frequency-based and the energy-based IMs of Table 3. Figs 5, 6, 7 show that the 'sufficiency' of an IM is not sensitive to the stiffness of the structure, at least for the structures considered herein, since for most cases the variation of the slope among the different frames is not substantial. Observe that, the examined IM levels are intentionally selected towards the left side of the fragility function, since ground motions with 

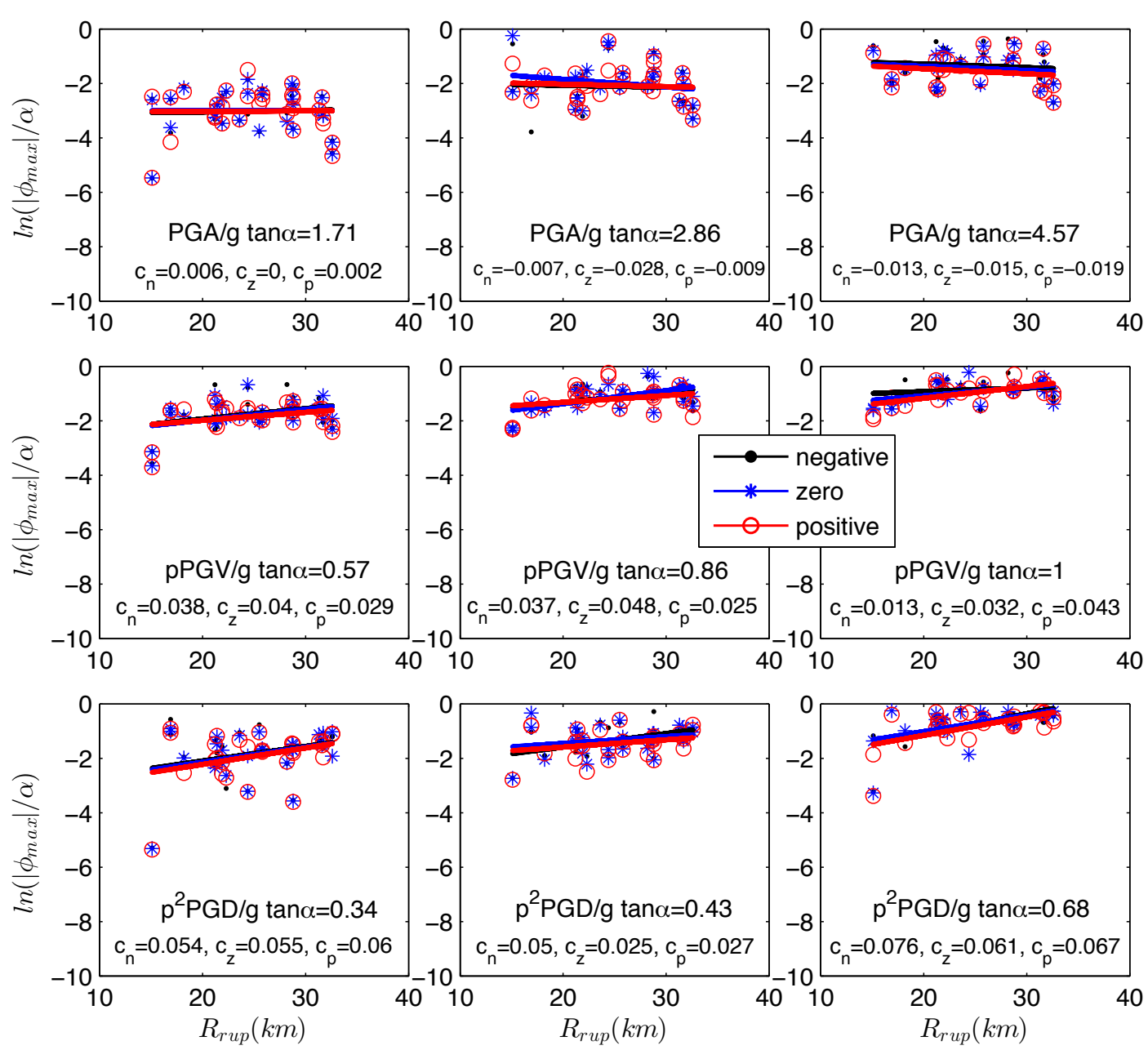

Figure 5: Regression analysis at various IM levels to examine the 'sufficiency' of the $I M_{1}=P G A / g$ tan $\alpha$, $I M_{2}=p P G V / g \tan \alpha, I M_{3}=p^{2} P G D / g \tan \alpha$ of Table 3 with respect to the distance from the fault $R_{\text {rup }}$ (Table 1). Constants $c_{n}, c_{z}$ and $c_{p}$ represent the slope of the linear regression and the closer to zero the more 'sufficient' the IM [28].

low-to-middle IM levels occur much more frequently than ground motions with high IM levels [7]. In addition, more 'safe rocking' cases occur at these IM levels, improving the accuracy of the results. Exception is the $I M_{7}=P G A / p P G V$ that 'safe rocking' action happens for higher $P G A / p P G V$ values. Among the slenderness-based IMs, Figs 5 and 6 show the 'insufficiency' of the $I M_{3}=p^{2} P G D / g \tan \alpha$ and for some IM levels (i.e., $\omega_{m} P G V / g \tan \alpha=2.14$ ) the 'insufficiency' of the $I M_{4}=\omega_{m} P G V / g \tan \alpha$. On the contrary, $I M_{1}=P G A / g \tan \alpha$ and $I M_{5}=A_{R M S} / g \tan \alpha$ show great 'sufficiency' with respect to the distance $R_{\text {rup }}$. Fig. 7 illustrates the 'insufficiency' of both the freguency-based and the energy-based IMs (i.e., $I M_{7}=$ $P G A / p P G V, I M_{8}=I_{F} / p^{0.75} R$ and $\left.I M_{9}=L_{e} / R\right)$.

\subsection{Fragility analysis}

This section compares the seismic fragility of the different rocking frames (freestanding and hybrid) by calculating the total probability of failure $P_{f}$ that a ground motion with IM $=\mathrm{x}$ causes the exceedance of a limit state (i.e., EDP $>$ LS3) and subsequently collapse (or 

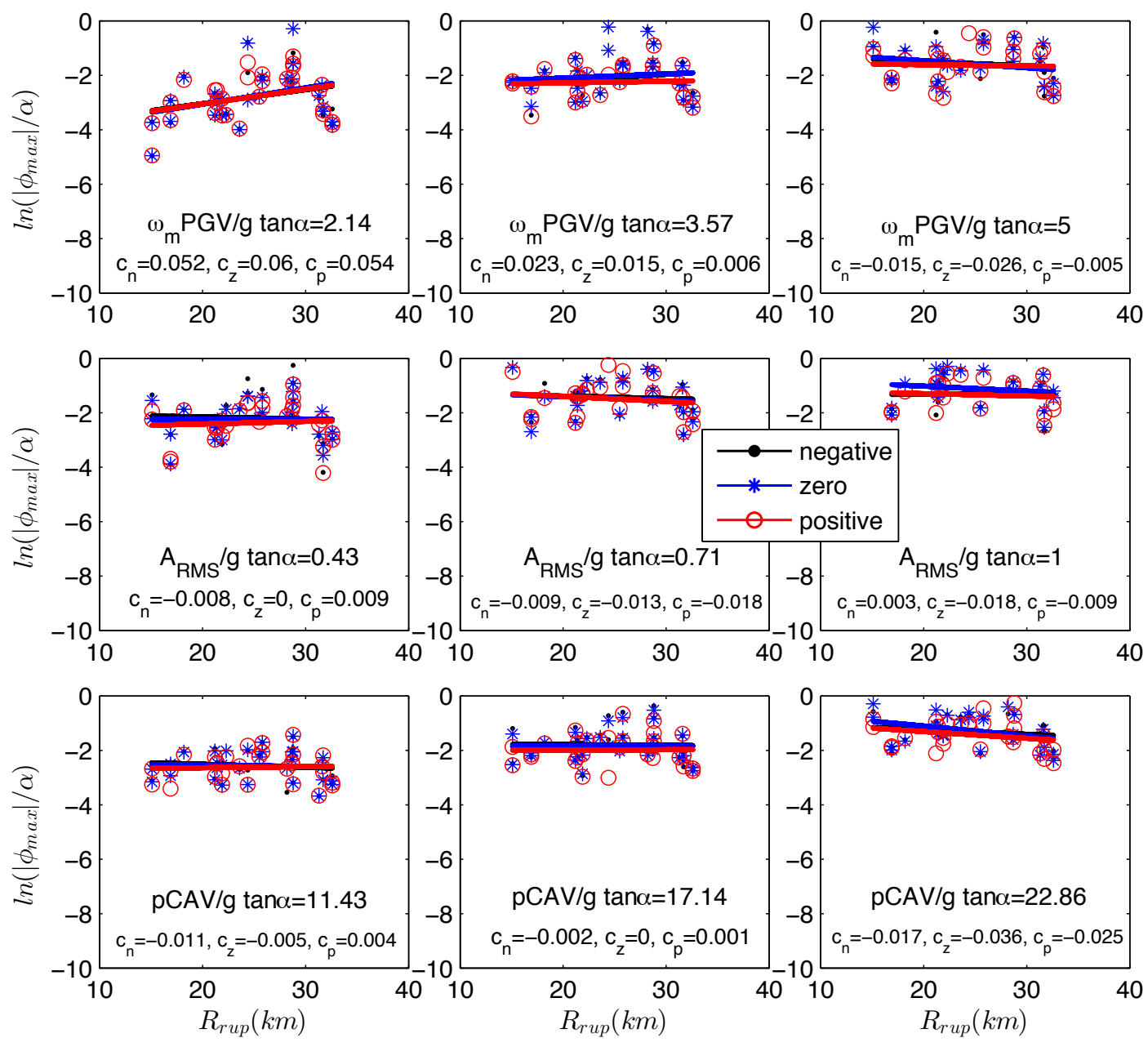

Figure 6: Regression analysis at various IM levels to examine the 'sufficiency' of the $I M_{4}=\omega_{m} P G V / g \tan \alpha$, $I M_{5}=A_{R M S} / g \tan \alpha, I M_{6}=p C A V / g \tan \alpha$ of Table 3 with respect to the distance from the fault $R_{\text {rup }}$ (Table 1). Constants $c_{n}, c_{z}$ and $c_{p}$ represent the slope of the linear regression and the closer to zero the more 'sufficient' the IM [28].

overturning) of the structure occurs. Adopting the multi-stripe analysis method [5,6], the limit state exceedance probability is calculated conditional on each intensity measure. To calculate the collapse probability, this study utilizes the logistic regression methodology. Note that, there are alternative methods to calculate the probability of collapse, e.g., the maximum likelihood estimation (MLE) [7]. Logistic regression, though, is consistent with maximum likelihood principles [7] and is commonly used to predict binary outcomes [35]. Specifically, since the structure either collapses or not (i.e., the EDP either exceeds the LS3 or not), collapse can be expressed with a 'categorical' variable [4]. This variable becomes zero when the structure does not collapse, and equal to one when it collapses.

Fig. 8 compares the seismic fragility of the hybrid FSHB rocking frames of Figs 1, 2 with the pertinent fragility of the archetypal freestanding frame for the most 'optimal' IMs based on the analysis in Section 3.2. Fig. 8 illustrates the mitigated fragility of the hybrid rocking frame with positive post-uplift lateral stiffness compared to the other rocking structural systems (freestanding and hybrid). In particular, the positive stiffness frame shows enhanced seismic 

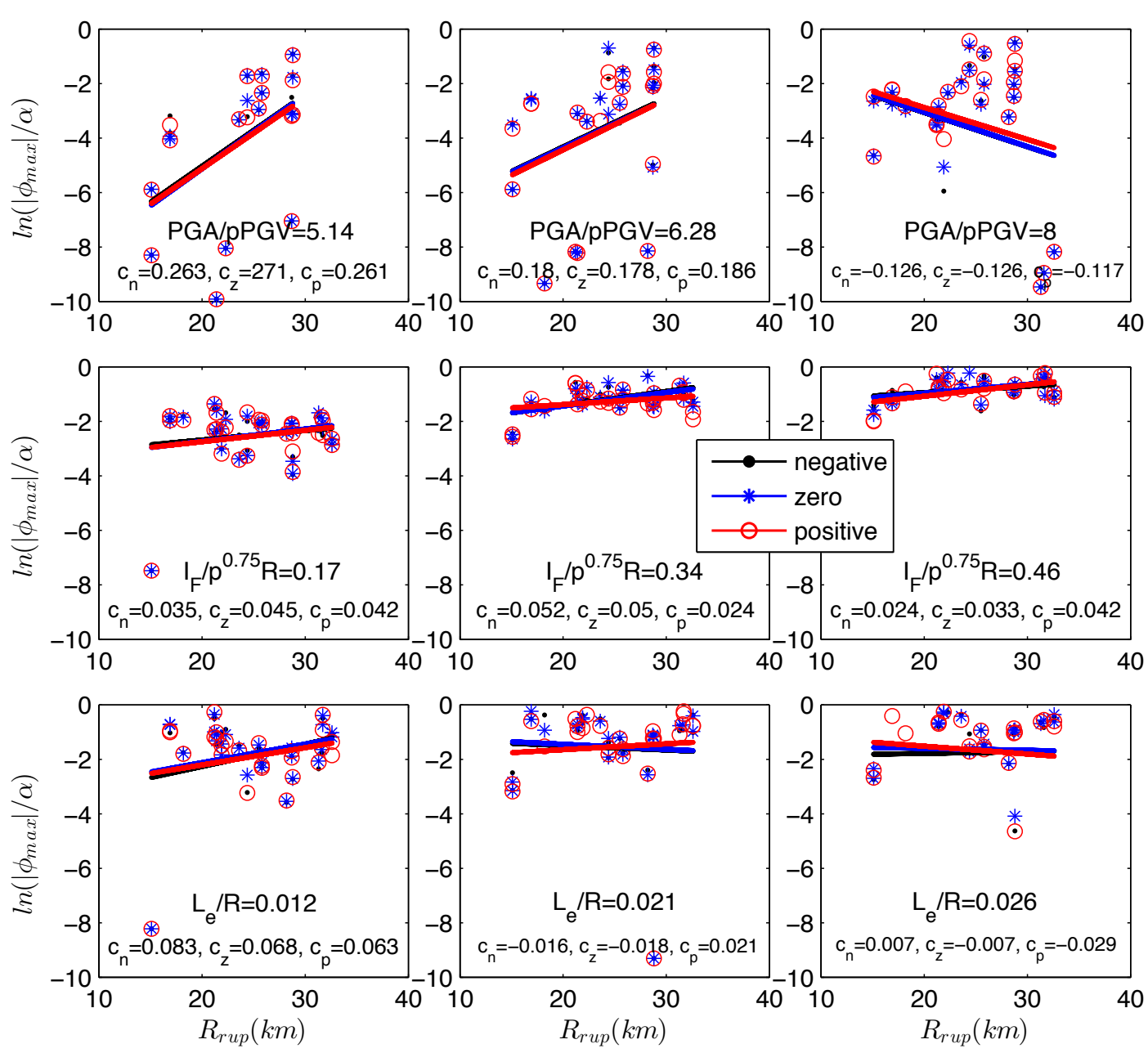

Figure 7: Regression analysis at various IM levels to examine the 'sufficiency' of the $I M_{7}=P G A / p P G V$, $I M_{8}=I_{F} / p^{0.75} R, I M_{9}=L_{e} / R$ of Table 3 with respect to the distance from the fault $R_{\text {rup }}$ (Table 1). Constants $c_{n}, c_{z}$ and $c_{p}$ represent the slope of the linear regression and the closer to zero the more 'sufficient' the IM [28].

performance for all 'optimal' IMs. For some IMs though, the distinction among the hybrid frames becomes marginal (i.e., for $P G A / g \tan \alpha$, or as $A_{R M S} / g \tan \alpha$ increases). Recall that, the present study ignores the fatigue of the supplemental devices (i.e., tendons and bucklingrestrained braces) and assumes that they continue to behave in a perfectly linear-elastic and nonlinear-hysteretic way respectively regardless of the number of rotation cycles. Another limitation is that it neglects the impact on the fragility of the accumulated energy dissipation by the BRBs. Giouvanidis and Dimitrakopoulos [24] showed that the enhanced seismic behavior of positive stiffness hybrid frames might come at the cost of higher energy demands by the dissipaters. A more complete approach would require the introduction of an additional EDP which characterizes the accumulated energy dissipation by the BRBs throughout the nonlinear response-history, or the consideration of a vector IM. This, however, is beyond the scope of the present work. 

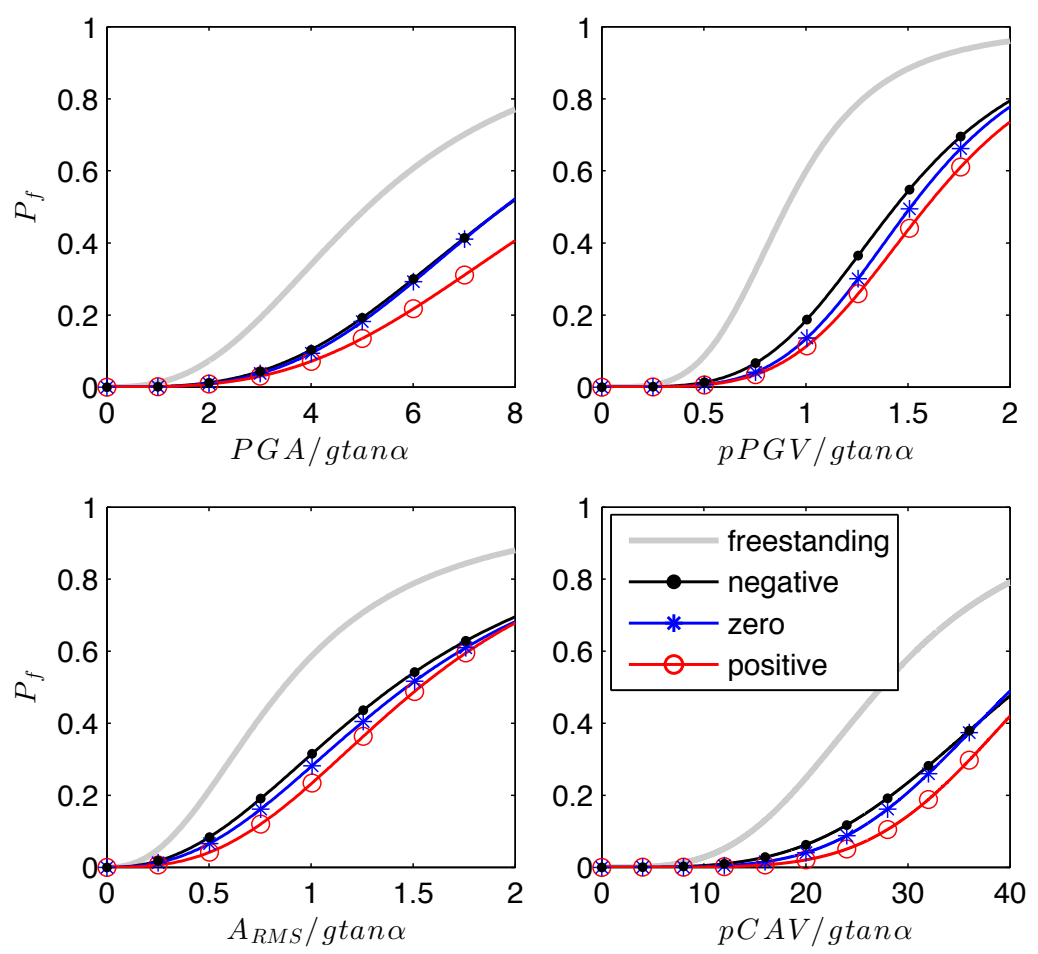

Figure 8: Failure prediction through seismic fragility curves of the freestanding and hybrid FSHB rocking frames for the most 'optimal' IMs adopting the logistic regression methodology.

\section{CONCLUSIONS}

This study investigates the existence of potentially 'optimal' intensity measures for hybrid rocking bridge frames by examining their 'practicality', 'efficiency' and 'sufficiency' with an appropriate engineering demand parameter. Specifically, this paper compares three categories of intensity measures, i.e., slenderness-based, frequency-based and energy-based IMs. The proposed slenderness-based IMs (e.g., PGA/gtan $\alpha, p P G V / g \tan \alpha, A_{R M S} /$ gtan $\alpha$ and $p C A V / g \tan \alpha$ ) exhibit reduced scatter on the response, lower logarithmic standard deviation and independence from seismic hazard parameters such as the distance from the fault. Hence, the slenderness-based IMs show higher 'practicality', 'efficiency' and 'sufficiency' compared to the other proposed IMs. In addition, this work investigates the seismic fragility of slender rocking bridge frames with fundamentally different dynamic behavior. It compares the seismic performance of rocking frames with negative, zero and/or positive post-uplift lateral stiffness with the archetypal freestanding frame in terms of their seismic fragility when subjected to the same suite of recorded earthquakes. The results unveil the mitigated fragility of the positive stiffness frame compared to rocking structures of zero or negative stiffness. However, for some intensity measures the seismic enhancement (in terms of fragility) becomes marginal. A more sophisticated approach would require the introduction of a second engineering demand parameter tailored to the needs of hybrid rocking structures or the consideration of a vector intensity measure. 


\section{REFERENCES}

[1] Acikgoz, S., DeJong, M. J., The interaction of elasticity and rocking in flexible structures allowed to uplift. Earthquake Engineering \& Structural Dynamics, 41(15), 2177-2194, 2012.

[2] Acikgoz, S., DeJong, M. J., The rocking response of large flexible structures to earthquakes. Bulletin of Earthquake Engineering, 12(2), 875-908, 2014.

[3] Acikgoz, S., DeJong, M. J., Analytical modelling of multi-mass flexible rocking structures. Earthquake Engineering \& Structural Dynamics, 45(13), 2103-2122, 2016.

[4] Agresti, A., Categorical data analysis, 3rd Edition. John Wiley \& Sons, 2012.

[5] Baker, J. W., Cornell, C. A., A vector-valued ground motion intensity measure consisting of spectral acceleration and epsilon. Earthquake Engineering \& Structural Dynamics, 34(10), 1193-1217, 2005.

[6] Baker, J. W., Cornell, C. A., Vector-valued intensity measures incorporating spectral shape for prediction of structural response. Journal of Earthquake Engineering, 12(4), 534-554, 2008.

[7] Baker, J. W., Efficient analytical fragility function fitting using dynamic structural analysis. Earthquake Spectra, 31(1), 579-599, 2015.

[8] Black, C. J., Makris, N., Aiken, I. D., Component testing, seismic evaluation and characterization of buckling-restrained braces. Journal of Structural Engineering, 130(6), 880894, 2004.

[9] Bouc, R., Forced vibration of mechanical systems with hysteresis. Proceedings of the 4th conference on non-linear oscillation, Prague, Czechoslovakia, 1967.

[10] Brogliato, B., Zhang, H., Liu, C., Analysis of a generalized kinematic impact law for multibody-multicontact systems, with application to the planar rocking block and chains of balls. Multibody System Dynamics, 27(3), 351-382, 2012.

[11] Cheng, C. T., Shaking table tests of a self-centering designed bridge substructure. Engineering Structures, 30(12), 3426-3433, 2008.

[12] DeJong, M. J., Amplification of rocking due to horizontal ground motion. Earthquake Spectra, 28(4), 1405-1421, 2012.

[13] DeJong, M. J., Dimitrakopoulos, E. G., Dynamically equivalent rocking structures. Earthquake Engineering \& Structural Dynamics, 43(10), 1543-1563, 2014.

[14] Dimitrakopoulos, E. G., Kappos, A. J., Makris, N., Dimensional analysis of yielding and pounding structures for records without distinct pulses. Soil Dynamics and Earthquake Engineering, 29(7), 1170-1180, 2009.

[15] Dimitrakopoulos, E. G., DeJong, M. J., Revisiting the rocking block: closed-form solutions and similarity laws. Proceedings of the Royal Society A: Mathematical, Physical and Engineering Science, 468(2144), 2294-2318, 2012. 
[16] Dimitrakopoulos, E. G., DeJong, M. J., Overturning of retrofitted rocking structures under pulse-type excitations. Journal of Engineering Mechanics, 138(8), 963-972, 2012.

[17] Dimitrakopoulos, E. G., Giouvanidis, A. I., Seismic response analysis of the planar rocking frame. Journal of Engineering Mechanics, 141(7), 04015003, 2015.

[18] Dimitrakopoulos, E. G., Paraskeva, T. S., Dimensionless fragility curves for rocking response to near-fault excitations. Earthquake Engineering \& Structural Dynamics, 44(12), 2015-2033, 2015.

[19] Dimitrakopoulos, E. G., Fung, E. D. W., Closed-form rocking overturning conditions for a family of pulse ground motions. Proceedings of the Royal Society A: Mathematical, Physical and Engineering Science, 472(2196), 20160662, 2016.

[20] Fajfar, P., Vidic, T., Fischinger, M., A measure of earthquake motion capacity to damage medium-period structures. Soil Dynamics and Earthquake Engineering, 9(5), 236-242, 1990.

[21] Giouvanidis, A. I., Dimitrakopoulos, E. G., Seismic analysis of hybrid rocking bridge bents. Proceedings of the 2nd European Conference on Earthquake Engineering and Seismology, Paper No 2251, Istanbul, Turkey, 2014.

[22] Giouvanidis, A. I., Dimitrakopoulos, E. G., Nonsmooth dynamic analysis of sticking impacts in rocking structures. Bulletin of Earthquake Engineering, 15(3), 2273-2304, 2017.

[23] Giouvanidis, A. I., Dimitrakopoulos, E. G., Seismic reliability assessment of rocking bridge bents with flag-shaped hysteretic behavior. Proceedings of the 16th World Conference on Earthquake Engineering, Paper No 1259, Santiago, Chile, 2017.

[24] Giouvanidis, A. I., Dimitrakopoulos, E. G., Seismic performance of rocking frames with flag-shaped hysteretic behavior. Journal of Engineering Mechanics, 143(5), 04017008, 2017.

[25] Giovenale, P., Cornell, C. A., Esteva, L., Comparing the adequacy of alternative ground motion intensity measures for the estimation of structural responses. Earthquake Engineering \& Structural Dynamics, 33(8), 951-979, 2004.

[26] Housner, G. W., The behavior of inverted pendulum structures during earthquakes. Bulletin of the Seismological Society of America, 53(2), 403-417, 1963.

[27] Kramer, S. L., Geotechnical Earthquake Engineering. Prentice-Hall International Series, 1996.

[28] Luco, N., Cornell, C. A.., Structure-specific scalar intensity measures for near-source and ordinary earthquake ground motions. Earthquake Spectra, 23(2), 357-392, 2007.

[29] Makris, N., Black, C. J., Dimensional analysis of rigid-plastic and elastoplastic structures under pulse-type excitations. Journal of Engineering Mechanics, 130(9), 1006-1018, 2004. 
[30] Makris, N., Vassiliou, M. F., Planar rocking response and stability analysis of an array of free-standing columns capped with a freely supported rigid beam. Earthquake Engineering \& Structural Dynamics, 42(3), 431-449, 2012.

[31] Makris, N., Vassiliou, M. F., Are Some Top-Heavy Structures More Stable?. Journal of Structural Engineering, 140(5), 06014001, 2014.

[32] Makris, N., Vassiliou, M. F., Dynamics of the rocking frame with vertical restrainers. Journal of Structural Engineering, 141(10), 04014245, 2014.

[33] Mander, J. B., Cheng, C. T., Seismic resistance of bridge piers based on damage avoidance design, Report No. NCEER-97-0014, University at Buffalo, 1997.

[34] Mavroeidis, G. P., Papageorgiou, A. S., A mathematical representation of near-fault ground motions. Bulletin of the Seismological Society of America, 93(3), 1099-1131, 2003.

[35] Neter, J., Kutner, M. H., Nachtsheim, C. J., Wasserman, W., Applied linear statistical models. McGraw-Hill, 1996.

[36] Padgett, J. E., Nielson, B. G., DesRoches, R., Selection of optimal intensity measures in probabilistic seismic demand models of highway bridge portfolios. Earthquake Engineering \& Structural Dynamics, 37(8), 711-725, 2008.

[37] Panagiotou, M., Trono, W., Jen, G., Kumar, P., Ostertag, C. P., Experimental seismic response of hybrid fiber-reinforced concrete bridge columns with novel longitudinal reinforcement detailing. Journal of Bridge Engineering, 20(7), 04014090, 2014.

[38] Priestley, M. J. N., Seible, F., Calvi, G. M., Seismic design and retrofit of bridges. John Wiley \& Sons, 1996.

[39] Psycharis, I. N., Fragiadakis, M., Stefanou, I., Seismic reliability assessment of classical columns subjected to near-fault ground motions. Earthquake Engineering \& Structural Dynamics, 42(14), 2061-2079, 2013.

[40] Rathje, E. M., Abrahamson, N. A., Bray, J. D., Simplified frequency content estimates of earthquake ground motions. Journal of Geotechnical and Geoenvironmental Engineering, 124(2), 150-159, 1998.

[41] Routledge, P. J., Cowan, M. J., Palermo, A., Low-damage detailing for bridges - A case study of Wigram-Magdala bridge. Proceedings, New Zealand Society for Earthquake Engineering 2016 Conference, Christchurch, New Zealand, 2016.

[42] Thonstad, T., Mantawy, I. M., Stanton, J. F., Eberhard, M. O., Sanders, D. H., Shaking Table Performance of a New Bridge System with Pretensioned Rocking Columns. Journal of Bridge Engineering, 21(4), 04015079, 2016.

[43] Trono, W., Jen, G., Panagiotou, M., Schoettler, M., Ostertag, C. P., Seismic response of a damage-resistant recentering posttensioned-hyfrc bridge column. Journal of Bridge Engineering, 20(7), 04014096, 2014. 
[44] Truniger, R., Vassiliou, M. F., Stojadinovic B., An analytical model of a deformable cantilever structure rocking on a rigid surface: experimental validation. Earthquake Engineering \& Structural Dynamics, 44(15), 2795-2815, 2015.

[45] Vamvatsikos, D., Fragiadakis, M., Incremental dynamic analysis for estimating seismic performance sensitivity and uncertainty. Earthquake Engineering \& Structural Dynamics, 39(2), 141-163, 2010.

[46] Vassiliou, M. F., Mackie, K. R., Stojadinovic B., Dynamic response analysis of solitary flexible rocking bodies: modeling and behavior under pulse-like ground excitation. Earthquake Engineering \& Structural Dynamics, 43(10), 1463-1481, 2014.

[47] Vassiliou, M. F., Truniger, R., Stojadinovic B., An analytical model of a deformable cantilever structure rocking on a rigid surface: development and verification. Earthquake Engineering \& Structural Dynamics, 44(15), 2775-2794, 2015.

[48] Vassiliou, M. F., Mackie, K. R., Stojadinovic B., A finite element model for seismic response analysis of deformable rocking frames. Earthquake Engineering \& Structural Dynamics, 46(3), 447-466, 2016.

[49] Vassiliou, M. F., Burger, S., Egger, M., Bachmann, J. A., Broccardo, M., Stojadinovic, B., The three-dimensional behavior of inverted pendulum cylindrical structures during earthquakes. Earthquake Engineering \& Structural Dynamics, doi:10.1002/eqe.2903, 2017.

[50] Wen, Y.-K., Method for random vibration of hysteretic systems. Journal of the Engineering Mechanics Division, 102(2), 249-263, 1976. 